\title{
IDENTIFICAÇÃO COM A MARCA: PROPOSIÇÃO DE UM INSTRUMENTO DE
}

\section{MEDIDA}

\author{
Eliane Cristine Francisco Maffezzolli \\ eliane.francisco@pucpr.br \\ Pontifícia Universidade Católica do Paraná - Curitiba, PR / Brasil \\ Paulo Henrique Muller Prado \\ paulo.prado@pucpr.br \\ Universidade Federal do Paraná - Curitiba, PR / Brasil
}

Recebido em 11/11/2012

Aprovado em 07/05/2013

Disponibilizado em 01/12/2013

Avaliado pelo sistema double blind review

Revista Eletrônica de Administração

Editor: Luís Felipe Nascimento

ISSN 1413-2311 (versão on-line)

Editada pela Escola de Administração da Universidade Federal do Rio Grande do Sul.

Periodicidade: Quadrimestral

Sistema requerido: Adobe Acrobat Reader.

\section{RESUMO}

Este estudo teve por objetivo desenvolver um modelo de mensuração sobre a identificação com a marca. Este construto compreende a congruência entre a imagem pessoal e a imagem de marca, desde que a marca consumida seja um símbolo significativo para a vida do consumidor e para os grupos sociais aos quais ele está vinculado. O suporte teórico desta variável contempla a Teoria de Identidade Social - SIT (TAJFEL, 1984) e a Teoria de Congruência do Self - SCT (SIRGY, 1986). A relevância deste construto se dá enquanto elemento facilitador e orientador das heurísticas de decisão do consumidor. O estudo empírico foi realizado em três etapas no contexto brasileiro: (1) estudo qualitativo exploratório, com 19 entrevistas em profundidade; (2) survey com 194 casos, com coleta via internet, e (3) levantamento com 780 casos, por meio de abordagem pessoal. Quatro marcas foram avaliadas na última etapa empírica: Volkswagen, Fiat, Honda e Renault. Os resultados demonstram que a identificação com marcas pode ser refletida por quatro dimensões: (1) cognitiva: relacionada com o conhecimento e experiência com a marca; (2) afetiva: que contempla o afeto e a conexão emocional desenvolvidos com a marca; (3) avaliativa: está associada ao julgamento pessoal e de terceiros sobre a marca utilizada; e (4) comportamental: observada pelo envolvimento e pelas ações tomadas em prol da marca. A Honda obteve o maior índice de identificação, seguida, respectivamente, da Volkswagen, Fiat e Renault. Por fim, também foi observado que, quanto maior é a identificação com a marca, maior é a tendência em permanecer com a marca em compras futuras. Portanto, a identificação com a marca pode oferecer à empresa uma fonte única de vantagem competitiva.

Palavras-chave: Identificação com a Marca; Teoria da Identidade Social; Teoria da Congruência do Self. 


\title{
BRAND IDENTIFICATION: A PROPOSAL OF A MEASUREMENT SCALE
}

\begin{abstract}
The objective of this research was to develop the brand identification measurement model. This construct reflects the congruence between the personal image and the brand image, since the consumed brand is an important symbol to the consumer life and for his/her social groups. The theoretical concept is based in the Social Identity Theory - SIT (TAJFEL, 1984) and the Self-Congruity Theory - SCT (SIRGY, 1986). The importance of this construct is given as a facilitator and advisor of the consumer decision heuristics. This study was conducted considering three steps in the Brazilian context: (1) exploratory qualitative research, with 19 deep interviews; (2) survey with 194 observations collected by internet, and (3) survey with 780 respondents, collected by personal approach. Four brands were evaluated in the last step: Volkswagen, Fiat, Honda and Renault. Results suggest that brand identification can be reflected by four dimensions: (1) cognitive: related to the consumer knowledge and experience with the brand; (2) affective: related to the affective and the emotional connection developed with the brand; (3) evaluative: related to the personal and others judgments about the consumed brand; and (4) behavioral: observed by the involvement and actions taken towards the brand. Honda has the highest rate of identification, then, respectively, Volkswagen, Fiat and Renault. Finally, it was also observed that the greater the identification with the brand, the greater the tendency to stay with the brand in future purchases. Therefore, identification with the brand can offer the company a unique source of competitive advantage.
\end{abstract}

Keywords: Brand Identification; Social Identity Theory; Self-Congruity Theory.

\section{INTRODUÇÃO}

Estudos acerca da relação entre identidade e marcas como, por exemplo, as extensões do self (BELK, 1988) e a identificação com empresas (BHATACHARYA; SEN, 2003; HILDEBRAND et al, 2008) sugerem a importância da pesquisa sobre elementos da identidade pessoal que orientam a afinidade, o gosto e a escolha por objetos consumidos. Recentemente, alguns estudos utilizaram o termo 'identificação com a marca' como uma forma de mostrar o apego, a escolha e a proximidade entre a imagem pessoal de um indivíduo e a imagem do símbolo comercial consumido (KUENZEL; HALLIDAY, 2008; TILDESLEY; COOTE, 2009; TUŠKEJ, GOLOB \& PODNAR, 2013). Lisjak, Lee \& Gardner (2012), demonstraram que esta relação pode ser tão significativa que uma ofensa à marca pode ser interpretada como uma ofensa pessoal. Stokburger-Sauer (2011) trata deste construto na esfera cultural, especialmente enquanto símbolo marcário de uma nação. Os autores afirmam a possibilidade de um indivíduo defender uma nação por compartilhar valores e manter um 
Identificação com a marca: proposição de um instrumento de medida

elo forte de identificação com a pátria. Entretanto, apesar da relevância do tema, ainda é incipiente na literatura o desenvolvimento teórico do significado da identificação e as possibilidades de mensuração desta variável. Portanto, o presente artigo versa sobre este gap teórico.

A relação entre consumidor e marca consumida, investigada nos estudos de relacionamento com marcas, está apoiada na estrutura cognitiva do consumidor. Isto implica na interpretação e decodificação de mensagens, símbolos e signos, capazes de orientar escolhas e decisões do consumidor. Sendo assim, o presente estudo é apresentado de acordo com os preceitos da psicologia social e cognitiva, e sugere especificamente duas teorias de apoio para compreender a complexidade do referido fenômeno: a teoria da identidade social SIT (TAJFEL, 1984) e a teoria da congruência do self - SCT (SIRGY, 1986). Tais teorias, quando utilizadas de forma conjunta, permitem a compreensão da origem da identificação, a qual parte dos processos perceptivos e, portanto, da capacidade cognitiva do consumidor em interpretar os símbolos utilizados pelas marcas.

Mais especificamente, a teoria de identidade social (SIT) (TAJFEL, 1984) trata da importância dos grupos sociais como fontes de reconhecimento e inserção da pessoa em grupos sociais. Tendo em vista que o ser humano é um ser social, a pertença em determinados grupos (família, trabalho, amigos, entre outros) é parte da vida e do equilíbrio psicológico de cada indivíduo. Portanto, avaliar a força da marca de acordo com esta perspectiva implica reconhecer que a marca, como símbolo social, pode, por exemplo, ser um elemento facilitador no processo de inclusão e de aceitação perante um grupo.

Já a teoria de congruência do self (SCT) (SIRGY, 1982; 1986) parte da avaliação de elementos que sejam congruentes à imagem do indivíduo e que proporcionem autoestima, autoconsistência e diferenciação. Desta forma, o consumo de certas marcas pode ter papel fundamental no reforço de imagem de um indivíduo na medida em que elas representem valores, crenças e imagens desejadas por seus consumidores.

A identificação com a marca representa, portanto, uma associação que o consumidor faz entre seu estilo, crenças e valores pessoais e o estilo, crenças e valores percebidos na imagem da marca consumida. Para o indivíduo, o processo de identificação é relevante porque representa um auxilio de reforço da sua identidade pessoal. Para a empresa, a identificação é importante na medida em que a marca ganha status de única ou de "melhor encaixe" para o consumidor (BURGERSS; HARRIS, 1999; BREWER; HEWSTONE, 2004). Neste sentido, para o gestor, a identificação com a marca oferece uma fonte única de vantagem competitiva

REAd | Porto Alegre - Edição 76 - N 3 - setembro/dezembro 2013 - p. 588-619 
para a empresa/marca (KUENZEL; HALLIDAY, 2008; TILDESLEY; COOTE, 2009; LISJAK; LEE \& GARDNER, 2012).

Além disto, ressalta-se que a relevância desta variável pode ser observada nas heurísticas do processo de escolha como: "compro/escolho marcas que mais têm a ver comigo e com o meu estilo". Portanto, a identificação é um vínculo simbólico percebido na direção do consumidor para com a marca. Alguns autores fizeram uso de uma medida unidimensional e simplificada da identificação, como Kuenzel \& Halliday (2008) e Tildesley \& Coote (2009), porém, tendo em vista a concepção original da SCT e da SIT, a proposta teórica de FranciscoMaffezzolli, Prado e Montaña (2010) parece estabelecer maior conexão com as teorias de suporte que explicam este fenômeno. Neste contexto, este estudo teve por objetivo desenvolver um modelo de mensuração multidimensional do construto identificação com a marca. Como produto secundário deste estudo, também foi realizada a avaliação e comparação deste construto entre marcas do setor automobilístico para analisar o efeito da identificação quanto à percepção de marcas que concorrem em um mesmo setor.

\section{REVISÃO DE LITERATURA}

A revisão de literatura aborda inicialmente os pressupostos da identidade social e da SIT, princípios de cognição e consistência e a SCT. Na sequência, é abordada a concepção teórica multidimensional da identificação com marcas, conforme proposição previa de Francisco-Maffezzolli, Prado e Montaña (2010). Por fim é apresentada uma breve reflexão sobre o mercado automobilístico brasileiro, como contexto empírico deste estudo.

\subsection{Identidade Social}

Identidade social é uma definição de identidade em consequência ao pertencimento do individuo em grupos sociais (TAJFEL, 1984; MORALES et al, 2009). Para compreender o processo de identidade social Morales et al (2009) ressaltam três elementos de referência, sendo eles: (1) os processos individuais, ou seja, a motivação pessoal e a relevância atribuída de acordo com o julgamento pessoal sobre a pertença a determinado grupo; (2) os processos grupais resultantes da comparação que o indivíduo faz entre os grupos em busca de uma distinção social positiva, e (3) os processos macro sociais, representados pelo contexto social em que o indivíduo está imerso e que permite espaço para as comparações anteriores. 
Identificação com a marca: proposição de um instrumento de medida

Neste contexto, cabe propor a reflexão: os indivíduos precisam de uma identidade social? De acordo com a psicologia social, a resposta é afirmativa. Para isto, entende-se que a identidade social é o elemento de união em um movimento coletivo, considerando as características e dinâmicas da sociedade contemporânea, onde "as pessoas sentem necessidade de uma identidade social" (MORALES et al 2009, p.788) preferencialmente positiva. A identidade social também está relacionada com o apego afetivo (HEERE; JAMES, 2007; KUENZEL; HALLIDAY, 2008; LISJAK; LEE \& GARDNER, 2012). De acordo com os autores, as pessoas fazem parte de grupos sociais no quais desejam ter e desenvolver laços emocionais.

Cabe mencionar ainda que a identidade social pode ser dotada de certa flexibilidade, na medida em que os indivíduos evoluem em maturidade, status de trabalho, entre outros. Portanto, ela pode ser alterada enquanto: (1) intensidade/valor da pertença do indivíduo no grupo ao longo do tempo; (2) valoração da pertença a um determinado grupo; (3) relevância da pertença, e 4) mudança no papel do indivíduo nos grupos (TAJFEL, 1984; WANN; BRASCOMBE, 1993; BREWER; HEWSTONE, 2004). Entretanto, conforme ressalta Tajfel (1984), não se trata de uma discussão sobre o que é identidade, mas sim, apenas compreender o aspecto social da identidade. Desta forma, as limitações sobre este termo, de acordo com a SIT, estão associadas a: (1) não dedicar esforço sem propósito ou demasiadamente longo sobre o significado de identidade, e (2) deixar claro que a definição da identidade do indivíduo é muito mais ampla e está associada à complexidade do self. No entanto, para o objetivo proposto e tratado pelo autor, basta reconhecer a limitação do termo quando do seu uso.

\subsubsection{Teoria de Identidade Social (SIT)}

A teoria de identidade social proposta por Henri Tajfel em meados da década de 70 é uma das teorias de maior influencia na psicologia social, iniciada com o estudo dos grupos mínimos (MORALES et al, 2009). A proposta de Tajfel era reconhecer como grupos pequenos (minorias) desenvolvem afinidades entre seus entes e estratégias para autodefesa. Segundo o autor, pessoas em mesma condição (exemplo, social, racial, entre outras) tendem a se aproximar na forma de grupos e estabelecer vínculos que podem resultar na respectiva inserção social ou no senso de pertença.

A categorização social, decorrente do processo de identidade social, pode ser compreendida como um sistema para auxiliar o indivíduo a criar e definir a sua posição em

REAd | Porto Alegre - Edição 76 - N 3 - setembro/dezembro 2013 - p. 588-619 
determinado meio social. Tajfel (1984) comenta algumas premissas que suportam esta afirmação: a) O indivíduo tende a ficar em grupos que sejam vantajosos para si; b) Se o indivíduo não está satisfeito, tenderá a mudar, a menos que 1) não possa mudar por questões objetivas, 2) entre em conflito com algum valor importante da sua autoimagem; c) Se o abandono demonstrar as dificuldades expostas anteriormente são sugeridas duas soluções 1) mudar a forma de interpretar o problema e 2) aceitar a situação, tal como é; e d) Nenhum grupo vive isolado, mas sim, contemplam a interação entre vários grupos. Portanto, os significados de pertença ficam mais claros na medida de comparação com outros grupos (BREWER; HEWSTONE, 2004; HEERE; JAMES, 2007).

A SIT tem sido utilizada ao longo dos anos em diversas áreas de conhecimento com o objetivo de compreender a relevância para o indivíduo sobre a pertença em grupos como elemento de afirmação de sua identidade (BURGERSS; HARRIS, 1999; BREWER; HEWSTONE, 2004). Portanto, parece plausível a relação proposta neste estudo sobre o vínculo entre o consumidor e suas marcas de consumo como elemento de inserção e reconhecimento social, haja vista que outros estudos (HEERE; JAMES, 2007; KUENZEL; HALLIDAY, 2008) propuseram abordagens semelhantes.

\subsection{Consistência e Cognição}

De acordo com Mower (1982), a cognição social está relacionada à como e o que os indivíduos pensam sobre questões sociais e sobre outras pessoas, inclusive elas mesmas, bem como sobre as atitudes, atribuições de características para os outros e para si mesmas, e a atração, no sentido de como e porque as pessoas se aproximam de certos grupos e de outros não. Em outras palavras, trata-se da forma pela qual a pessoa define a sua identidade pessoal e social e como decide sobre a inserção em determinados grupos similares a ela e aos seus objetivos. Já a consistência, característica de coesão das decisões do indivíduo, oferece suporte para compreender as respostas e escolhas que mais se assemelham ao seu contexto de vida (BURGERSS; HARRIS, 1999; BREWER; HEWSTONE, 2004; MITTAL, 2006; PARKER, 2009). Está implícita neste conceito certa associação com a lógica da congruência, na medida em que as escolhas do indivíduo reforçam suas crenças e valores (DOLICH, 1969; SIRGY, 1982; 1986). Portanto, é no contexto de interpretação do meio social e de coesão nas decisões do indivíduo com seu respectivo self que se encontra a SCT, melhor detalhada no item a seguir.

REAd | Porto Alegre - Edição 76 - N 3 - setembro/dezembro 2013 - p. 588-619 
Identificação com a marca: proposição de um instrumento de medida

\subsubsection{Teoria da Congruência do Self (SCT)}

A teoria de congruência do self proposta por Sirgy (1986) deriva da contribuição de quatro principais elementos, sendo eles:

1) A SCT está relacionada a compreender como o self se aproxima (ou não) de imagens percebidas de objetos, pessoas ou eventos, sendo estes relacionados a um fenômeno de cognição, avaliação e informação.

2) A SCT está relacionada com a dinâmica da personalidade, ou seja, considera as características do indivíduo como um todo.

3) A SCT está associada à cognição social e aos elementos de percepção, avaliação, força e valência.

4) A SCT está relacionada à teoria cibernética e de sistemas porque contempla a congruência de várias fontes de informação que, por sua vez, permitem um sistema de comparação.

Conforme proposto por Sirgy $(1982 ; 1986)$ os elementos autoestima e autoconsistência estão associados a uma dupla avaliação: privada e pública. $\mathrm{O}$ autor comenta que este é um dos elementos de principal motivação para a ação dos indivíduos e que além da preocupação individual que se tem sobre escolhas e comportamento, esta faceta da congruência também está preocupada em manter um padrão de acordo com a perspectiva de outras pessoas. Estudos de Dolich (1969) e Parker (2009) demonstram a relevância da congruência por meio da análise da imagem das marcas consumidas e da imagem pessoal dos indivíduos há, pelo menos, quatro décadas.

\subsection{Identificação com a Marca}

O termo "identificação" foi criado em 1950 no sentido de apropriação e comprometimento de uma identidade (BERGAMI; BAGOZZI, 2000). A identificação do consumidor com a empresa (Consumer-Company Identification) foi desenvolvida nos estudos de Bhattacharya e Sen (2003) e Hildebrand et al (2008) como um conceito que ilustra o quanto uma pessoa pode "parecer" com uma empresa, tendo em vista a forma esta como se mostra para o mercado. No entanto, o foco dos autores foi maior no sentido de empresa enquanto organização, do que como uma marca de consumo final. Desta forma, sugere-se que pode haver maior identificação de consumidoras com a marca OMO do que com a marca Unilever.

REAd | Porto Alegre - Edição 76 - Nº 3 - setembro/dezembro 2013 - p. 588-619 
Desta forma, a identificação com a marca trata da transposição que o indivíduo pode fazer dos valores, crenças e imagem de uma marca, sobre a definição e/ou reafirmação da sua própria identidade, considerando a congruência entre a imagem da marca e a imagem pessoal e a relação com os grupos sociais que o individuo pertence. Este termo foi recentemente utilizado por Kuenzel e Halliday (2008), Tildesley e Coote (2009), Stokburger-Sauer (2011) e Tuškej, Golob \& Podnar (2013). No entanto, os autores não especificam com clareza o suporte teórico de origem deste termo. Kuenzel e Halliday (2008) chegam a mencionar a SIT, mas não desenvolvem uma relação conceitual sobre a identificação com marca. Sendo assim, para compreender o conceito de identificação com marca, considera-se que o consumidor interpreta mensagens sobre a identidade da marca, compara com a identidade pessoal e se apropria da marca como elemento de inserção social e aceitação em determinados grupos. Além disto, a manifestação da identificação com marcas é decorrente de um processo mapeado inicialmente por ser multidimensional (FRANCISCO-MAFFEZZOLLI; PRADO; MONTAÑA, 2010). Desta forma, segue o detalhamento de cada dimensão em análise neste estudo.

\subsubsection{Dimensões da Identificação com a Marca}

De acordo com as teorias de base neste estudo, SIT e CST, quatro dimensões são destacadas para compreender o processo de manifestação da identificação com a marca: (1) uma estrutura cognitiva (BURGESS; HARRIS, 1999; HEERE; JAMES, 2007), (2) um elemento afetivo, a qual representa o apego emocional em relação a determinado grupo (ZAMBARDINO; GOODFELLOW, 2007; HEERE; JAMES, 2007) (3) um aspecto de avaliação, representado pelo valor em relação aos demais grupos (BURGESS; HARRIS, 1999; ASHMORE; DEAUX \& MACLAUGHLIN-VOLPE, 2004; HEERE; JAMES, 2007) e (4) um aspecto comportamental (ASHMORE; DEAUX \& MACLAUGHLIN-VOLPE 2004; HEERE; JAMES, 2007). A figura 1 ilustra a composição da identificação com marca sugerida no presente estudo.

REAd | Porto Alegre - Edição 76 - N 3 - setembro/dezembro 2013 - p. 588-619 
Identificação com a marca: proposição de um instrumento de medida

\begin{tabular}{|c|c|c|}
\hline $\begin{array}{c}\text { Dimensão Cognitiva } \\
\text { É o nível de conhecimento de uma } \\
\text { marca obtido por meio de } \\
\text { experiências diretas ou indiretas. }\end{array}$ & $\begin{array}{c}\text { Dimensão de Avaliação } \\
\text { É a avaliação pessoal e a de } \\
\text { terceiros sobre a marca e como ela } \\
\text { está associada a determinado grupo } \\
\text { social. }\end{array}$ \\
\hline $\begin{array}{c}\text { Dimensão Afetiva } \\
\text { identificação que ocorre por meio } \\
\text { da empatia e proximidade coma } \\
\text { marca. }\end{array}$ & $\begin{array}{r}\text { DENTIFICAÇÃO } \\
\text { COM A MARCA }\end{array}$ \\
$\begin{array}{c}\text { É o nível de envolvimento e ação de } \\
\text { um indivíduo em prol de uma } \\
\text { marca. }\end{array}$ \\
\hline
\end{tabular}

Figura 1 - Proposta teórica de dimensões para a Identificação com Marca Fonte: elaborado pelos autores

a) Dimensão Cognitiva: Está associada ao nível de conhecimento que uma pessoa tem de uma marca decorrente da sua experiência pessoal ou de terceiros (HEERE; JAMES, 2007, p.6; UNDERWOOD; BOND \& BAER, 2001). Esta dimensão também está associada à proposição teórica de Ashmore, Deaux e Maclaughlin-Volpe (2004), chamada "conteúdo e significado". Sendo assim, a história da marca, a presença no mercado, a troca de experiência com outros consumidores, entre outros, demonstram o arcabouço de conhecimento que uma pessoa pode ter sobre uma marca. Portanto, o reconhecimento cognitivo parte da experiência que o indivíduo tem com uma marca, e da relação que ele faz sobre quem a marca é, quais são os valores e imagem da empresa e qual a influência da marca na vida da pessoa (BURGESS; HARRIS, 1999; BREWER; HEWSTONE, 2004). Neste contexto é apresentada a proposição de estudo 1:

p1: a dimensão cognitiva reflete de forma positiva e significativa parte do processo de identificação com a marca.

b) Dimensão Afetiva: É aceito na literatura que marcas são construídas por meio de uma combinação de elementos racionais e emocionais que, juntos, orientam o processo de compra. Portanto, as marcas contemplam um apelo duplo: para a cabeça e para o coração (ZAMBARDINO; GOODFELLOW, 2007). Além disto, as marcas estão carregadas de significados que podem reforçar o estilo e a própria imagem do consumidor (SCHOUTEN; MCALEXANDER, 1995; FOURNIER, 1998). As escolhas realizadas permitem ao indivíduo uma apropriação da imagem atribuída à marca para uma referência pessoal. Desta forma, é possível inferir que os consumidores formam conexões entre marcas e seus respectivos autoconceitos (ESCALAS; BETTMAN, 2005). Tais conexões são desenvolvidas por certa afinidade e gosto da pessoa pelos objetos e marcas de utilizadas, conforme o sentido de 
congruência postulado na SCT. Esta situação caracteriza a relação afetiva da identificação, conforme postula a segunda proposição deste estudo:

p2: a dimensão afetiva reflete de forma positiva e significativa parte do processo de identificação com a marca.

c) Dimensão de Avaliação: A avaliação é definida como "a atitude positiva ou negativa que uma pessoa tem na direção da categoria social em questão" (ASHMORE, DEAUX \& MACLAUGHLIN-VOLPE, 2004:83). Esta atitude por sua vez, pode ser influenciada por dois julgamentos, sendo eles, o privado e o público. O primeiro, diz respeito à forma como o indivíduo vê a si próprio. O segundo está associado à forma como os outros percebem o indivíduo (HEERE; JAMES, 2007). A avaliação implica no "saldo" resultante das vantagens do uso da marca e reforça a questão de reconhecimento e inserção social do indivíduo (BURGESS; HARRIS, 1999; BREWER; HEWSTONE, 2004). Desta forma, tem-se que:

p3: a dimensão avaliativa reflete de forma positiva e significativa parte do processo de identificação com a marca.

d) Dimensão de Comportamento (ou Comportamental): está associada ao "o nível em que uma pessoa se envolve em ações que implicam diretamente na identidade do grupo da categoria em questão". (ASHMORE; DEAUX \& MACLAUGHLIN-VOLPE, 2004: 83). Este termo também está relacionado a um interesse particular em manter a identidade do indivíduo com o grupo. Por exemplo, o envolvimento comportamental com times esportivos. Neste caso, a dimensão comportamental seria mais intensa na medida em que o indivíduo assiste à maior quantidade de jogos possíveis, compra e usa uniforme e outros apetrechos do time, fala com outras pessoas, faz indicações e recomendações sobre o time. Portanto, esta dimensão contempla os interesses, a capacidade de diferenciação bem como a situação em que o individuo se encontra para demonstrar o quão envolvido está (ou não) no processo de identificação com uma marca, conforme relações esperadas no processo de formação da identidade social (BURGESS; HARRIS, 1999). Neste sentido, segue a proposição 4:

p4: a dimensão comportamental reflete de forma positiva e significativa parte do processo de identificação com a marca.

\subsection{O Setor Automotivo Brasileiro}

REAd | Porto Alegre - Edição 76 - N 3 - setembro/dezembro 2013 - p. 588-619 
Identificação com a marca: proposição de um instrumento de medida

Desde 2010 o Brasil conta com o maior número de montadoras instaladas do mundo, sendo em 2013 o sétimo maior produtor de veículos, quinto maior produtor de caminhões e o primeiro produtor mundial de ônibus (ANFAVEA, 2013).

O Brasil foi um dos países em que este setor teve menor retração com o impacto da crise de 2008/2009. Tal situação mostra que o crescimento da indústria se deve em grande parte ao consumo local, ou seja, além de ser um dos maiores produtores do mundo, passou a ser alvo de consumo para as montadoras. Em agosto de 2012 o país ocupava o quarto local mundial de consumo deste bem. Atualmente, existem mais de 28 diferentes marcas de fabricantes, com 57 plantas industriais. A competição neste setor está muito mais acirrada nos últimos dez anos. As projeções de crescimento do mercado automobilístico brasileiro estimam 42 milhões de novos carros até 2020 (ANFAVEA, 2013). Desta forma, os elementos de diferenciação do produto não estão apenas em acabamentos ou detalhes mecânicos, mas também nas características simbólicas da marca. As novas marcas precisam conquistar mercado e as marcas tradicionais no cenário brasileiro buscam consolidação dentre os consumidores. Tal contexto de competição, somado à importância declarada desta categoria de produto na fase qualitativa deste estudo guiaram a definição de quatro marcas a serem comparadas na última etapa empírica: Volkswagen, Fiat, Renault e Honda.

\section{METODOLOGIA}

Este estudo foi realizado em três diferentes etapas. A primeira etapa é caracterizada como qualitativo-preparatória (MALHOTRA, 2006). O objetivo foi buscar maior compreensão das relações entre consumidores e marcas consumidas, principalmente sobre o significado da força da marca para o indivíduo, bem como compreender a relação entre sua imagem/personalidade e as marcas identificadas como mais próximas e mais relevantes para ele. Nesta fase, consumidores com diferentes perfis sócio demográficos foram entrevistados, conforme quadro 1. Não foi definida uma categoria de produtos para que estas informações pudessem emergir do campo. Procedimento semelhante foi observado em Fournier (1998). A heterogeneidade do grupo entrevistado considerou dois principais critérios: gênero e idade. Sendo assim, 18 homens e mulheres entre 20 a 60 anos foram entrevistados. Esta etapa serviu de apoio complementar a base teórica para o desenvolvimento da escala de medida, bem como para a definição do contexto empírico das outras fases de pesquisa. Para análise de dados foi utilizada análise de narrativas e de conteúdo (BARDIN, 2004).

A segunda etapa teve caráter quantitativo-preparatório (HAIR JUNIOR et al., 2005), REAd | Porto Alegre - Edição 76 - N 3 - setembro/dezembro 2013 - p. 588-619 
e teve por objetivo servir de etapa preparatória para a elaboração do instrumento de medida da identificação com a marca. Foram conduzidas 194 observações. O instrumento de coleta utilizado contemplou questões fechadas com escalas bietápicas de 6 pontos no intuito de checar a mensuração das variáveis propostas. Para a análise, foi conduzida análise fatorial exploratória e verificado o índice Alfa de Cronbach para checar a consistência das escalas. Esta fase foi conduzida por meio de 194 questionários válidos coletados via internet por homens e mulheres que possuíssem carro próprio de diferentes marcas. As etapas 2 e 3 deste estudo focam no setor empírico automobilístico.

Quadro 1 - Descrição do perfil dos respondentes da fase qualitativa

\begin{tabular}{|c|c|c|c|c|c|c|c|}
\hline Entrevistado & Gênero & Idade & $\begin{array}{c}\text { Estado } \\
\text { civil }\end{array}$ & Classe social & Profissão & NI* & Referência \\
\hline Entv1 & \multirow{9}{*}{$\begin{array}{l}\stackrel{̊}{\Xi} \\
\stackrel{\Xi}{\Xi} \\
\stackrel{\Xi}{\Xi}\end{array}$} & 24 & solteiro & B1 & Estudante & SI & Carlos \\
\hline Entv2 & & 29 & casado & B1 & Engenheiro & $S$ & Alexandre \\
\hline Entv3 & & 31 & casado & B1 & Economista & $\mathrm{P}$ & Marcelo \\
\hline Entv4 & & 36 & casado & B1 & Militar & $\mathrm{P}$ & Roberto \\
\hline Entre5 & & 43 & casado & B1 & Professor & $\mathrm{P}$ & Ricardo \\
\hline Entv6 & & 43 & casado & $\mathrm{B} 2$ & Rep. comercial & MI & João \\
\hline Entv7 & & 44 & casado & B1 & Designer gráfico & $\mathrm{P}$ & Marcos \\
\hline Entv8 & & 51 & solteiro & A2 & Consultor & $\mathrm{M}$ & José \\
\hline Entv9 & & 59 & casado & $\mathrm{B} 2$ & Aposentado & MI & Antonio \\
\hline Entv10 & \multirow{10}{*}{ 弯 } & 21 & solteira & $\mathrm{B} 2$ & Estudante & MI & Alice \\
\hline Entv11 & & 25 & casada & $\mathrm{A} 2$ & Estudante & SI & Ana \\
\hline Entv12 & & 28 & casada & $\mathrm{B} 1$ & Bancária & $\mathrm{S}$ & Ruth \\
\hline Entv13 & & 33 & casada & B1 & Professora & $\mathrm{M}$ & Julia \\
\hline Entv14 & & 35 & casada & B1 & Do lar & $\mathrm{MC}$ & Maria \\
\hline Entv15 & & 43 & casada & $\mathrm{B} 2$ & Professora & $\mathrm{P}$ & Malu \\
\hline Entv16 & & 48 & solteira & B1 & Bancária & $\mathrm{P}$ & Joana \\
\hline Entv17 & & 54 & casada & B2 & Do lar & MI & Karen \\
\hline Entv18 & & 54 & casada & B1 & Do lar & MI & Diva \\
\hline Entv19 & & 58 & casada & $\mathrm{B} 2$ & Vendedora & $\mathrm{MC}$ & Lucia \\
\hline
\end{tabular}

*Nível de Instrução: MI (Médio Incompleto) / MC (Médio Completo) / S (Superior Completo) / SI (Superior Incompleto) / P (Pós graduação lato sensu) / M (Mestrado/Doutorado).

Fonte: Elaborado pelos autores

A terceira etapa foi definida como quantitativa descritiva (MALHOTRA, 2006). Nesta fase foi conduzido um survey com caráter cross-sectional para fins de teste do modelo proposto com 780 observações. O perfil amostral foi não probabilístico por cotas (MALHOTRA, 2006). As cotas foram geradas a partir de 4 marcas escolhidas para fins de comparação durante o processo de análise, sendo elas: Volkswagen, Renault, Honda e Fiat. A 
Identificação com a marca: proposição de um instrumento de medida

escolha por estas marcas ocorreu por alguns critérios como: possuir loja própria da marca na cidade de coleta dos dados (Curitiba) e ofertar um portfólio de veículos que contemplasse carros populares e de luxo. Além disto, foram escolhas marcas de diferentes países de origem. A análise dos dados desta terceira teve foco na CFA da identificação com marcas e comparativos entre marcas, segundo os padrões de qualidade propostos por Hair Junior et al (2005).

\section{ANÁLISE DOS RESULTADOS}

Os resultados são apresentados conforme os principais achados de cada etapa de pesquisa. Desta forma inicia-se com a etapa qualitativa, seguida das fases de levantamento. Por fim, as comparações entre marcas são realizadas.

\subsection{Etapa Qualitativa}

Esta etapa contemplou entrevistas guiadas por um roteiro semi-estruturado. Incialmente os entrevistados foram convidados a falarem sobre si e comentarem características pessoais, traços de personalidade, gostos, hábitos, crenças e valores. Em seguida eram convidados a falar sobre marcas que tinham uma forte presença na vida pessoal. Desta forma os entrevistados relataram histórias pessoais de uso de várias marcas, conforme se sentiam mais a vontade. Diva, por exemplo, como responsável do lar, espontaneamente falou de marcas de produtos a serem consumidos pela família, especialmente Nestlé e Todeschini. Desta forma, 39 marcas foram citadas espontaneamente dentre os 18 entrevistados. A saber: Decatlon, Gianini, Toyota, Nestlé, Suzuki, Ades, Makenji, Gillete, Bic, Electrolux, Davene, Buterfly, HP, Microsoft, Natura, Qualy, Ferracini, Apple, Guaraná Antarctica, Volkswagen, Vinhos Del Rei, Dove, Peti Way, Avon, Sony, Mizuno, Mercedes Benz, Café Damasco, Sanyo, O Boticário, Nike, Carolina Castro, Marina de Bourbon, Zutti, Ford, União, Coca-Cola, Todeschini (alimentos), Johnson \& Johnson. Cada marca citada foi declarada como símbolo de identificação pelos respondentes. Tal situação sugere indícios de que a identificação com a marca pode ocorrer com diferentes categorias de produto. Desta forma, sugere-se que o fenômeno da identificação com marcas possa ter extensão em diversos segmentos de consumo que caracterizem uma relação B2C.

Inicialmente os respondentes afirmaram o conhecimento da marca tendo em vista suas experiências (atuais e no passado), as quais garantem ao indivíduo a sensação de que eles reconhecem na marca aspectos que merecem ser valorados, conforme observado na literatura

REAd | Porto Alegre - Edição 76 - N 3 - setembro/dezembro 2013 - p. 588-619 
(DIMMOCK; GROVE \& EKLUND, 2005; HEERE; JAMES, 2007). Por exemplo, quando Diva e Alexandre comentam sobre a Nestlé, mesmo com diferenças de gênero, idade e ciclo de vida, ambos os entrevistados comentam a experiência com a marca Nestlé desde a infância: "Lembro desta marca desde minha infância, quando minha mãe usava" (Diva) e ainda "Esta marca me lembra quando eu era pequeno" (Alexandre). Alexandre também fala sobre a Toyota e a Suzuki, e afirma: "conheço a preocupação ambiental que estas empresas [Toyota e Suzuki] têm e demonstram no mercado", fato que sugere a relação entre o nível de conhecimento de valores, tradição, experiência com a marca e a identificação com marcas. Tal situação de conhecimento e experiência com a marca está alinhada a estudos anteriores que oferecem suporte à dimensão cognitiva da identificação com a marca (WANN; BRASCOMBE; 1993; BURGESS; HARRIS, 1999; BREWER; HEWSTONE, 2004; HEERE; JAMES, 2007)

Além disto, os entrevistados falaram sobre o "gostar da marca" como característica importante para a seleção que tinham feito. Este fato reforça a afinidade com a marca, conforme comentário de Marcos: "[...] eu gosto bastante da Apple. Acho que tem bastante a minha cara [...] gosto do design deles”. Esta situação, já observada nos estudos de Heere e James (2007), revela a relação afetiva entre o indivíduo e as marcas consumidas. Porém, ressalta-se que diferentes categorias de produto desenvolvem esta percepção nos indivíduos. Portanto, a valorização e o apego a certas marcas dependem do perfil/estilo da pessoa. Além disto, o argumento de "reforça quem eu sou", conforme disse Joana ao se referir a Zutti, dá suporte a esta parte afetiva da identificação. Esta manifestação possível de afeto e apego por uma marca consumida foi preconizada nos estudos de Zambardino e Goodfellow (2007) e Pawle e Cooper (2006).

Já a situação comentada por Marcelo evidencia a importância da opinião de terceiros sobre a imagem pessoal:

“[...] quando eu era gerente da loja (...) eu deixava meu paletó na cadeira para trabalhar durante o dia quando não tinha que atender cliente. Daí uma vez era perto do meu aniversário e uma amiga foi ver qual era marca no colarinho para comprar o presente (...) Depois, quando teve a festa, ganhei uma camisa desta marca [Makenji] e meus amigos falaram: ah!, é da Makenji, hein?! Achei engraçado na hora, mas depois me senti bem porque vi outras pessoas comprando coisas desta marca. Virei referência" (Marcelo)

Por outro lado, existe também a avaliação pessoal como elemento de julgamento sobre 
Identificação com a marca: proposição de um instrumento de medida

a relevância da marca consumida. Neste caso, É possível perceber o conforto e a tranquilidade no uso da marca unicamente porque o usuário acredita que a marca será um apoio certeiro na atividade a ser realizada. Tal situação fica evidente no discurso de Karen: "o cafezinho é minha marca registrada, por isto, tem que ser União. Eu sei que a marca é boa”. Esta situação avaliativa aparece de forma similar em estudos anteriores (BURGESS; HARRIS, 1999; HEERE; JAMES, 2007), e reforça a importância desta faceta da identidade social para os indivíduos. Estas situações oferecem suporte à dimensão de avaliação da identificação.

Em termos comportamentais, a adesão a eventos ou comunidades (virtuais) de determinadas marcas não foi percebida de forma unânime. Dependendo do perfil da pessoa, bem como da avaliação pessoal sobre cada marca consumida, as ações que implicam maior proximidade com a marca, como a busca de informações ou a adesão a comunidades em mídias sociais ou eventos, depende da categoria de produtos e do perfil do consumidor. Para Marcos, acompanhar as inovações da marca Apple, é muito relevante: “ah!, estar conectado com a Apple é bom porque daí sei tudo o que acontece. É sempre bom ser um dos primeiros a saber". Também Ricardo menciona a importância de estar atualizado no meio pessoal e profissional em termos de tecnologia. Diva comentou sobre sua rede off line em termos de troca de receitas com vizinhas, fato que envolve constantemente a marca Nestlé. Neste sentido dispor de tempo e esforço pessoal para incluir a marca em atividades rotineiras de forma intencional implica em compreender a proximidade da pessoa com a marca. Esta relação próxima da marca enquanto parte da vida do individuo foi observada no estudo de Schouten e Mcalexander (1995). Heere e James (2007) demonstraram em estudo empírico que esta manifestação comportamental pode ficar evidente de acordo com a quantidade de produtos que o individuo tem de certa marca preferida para consumo.

Portanto, conforme previsto na literatura de apoio, foi possível observar a relevância das dimensões propostas para a análise da identificação com a marca, sendo elas, cognitiva, afetiva, avaliativa e comportamental nas narrativas espontâneas dos entrevistados. Esta parte do estudo serviu de insight para a geração da escala de medida para esta variável, além da consulta prévia às teorias de suporte. De todas as marcas e categorias de produto citadas nesta fase, optou-se por seguir o estudo com marcas do setor automotivo, dado o apego entre consumidor e o produto, bem como a relevância econômica deste setor no cenário nacional. Esta categoria de produto foi uma das mais citadas com variações entre Mercedes Benz, Toyota, Volkswagen e Ford. 


\subsection{Etapa 2: quantitativo-preparatório}

Os respondentes desta etapa foram abordados via internet (software Qualtrics), com o objetivo de verificar a capacidade de o instrumento de coleta mensurar a identificação com a marca. Para isto, foi estabelecido filtro com quatro principais características: ser brasileiro e residir no Brasil, ser maior de 18 anos e possuir pelo menos um carro para uso pessoal.

Ao todo foram 194 respondentes com média de idade de 37 anos ( $d p=10,909$, mínimo de 21 e máximo de 71 anos), sendo que $69 \%$ dos casos registraram idade entre 21 e 40 anos. A classe social predominante foi $\mathrm{A}$ e $\mathrm{B}$, fato coerente com a proporção de usuários de internet nas regiões de origem dos respectivos respondentes e próxima à classificação dos respondentes da fase qualitativa. A distribuição geográfica concentrou mais pessoas no Paraná (estado de origem da pesquisa, especificamente, Curitiba), embora também haja respondentes de outros estados da região sul, norte, sudeste. Sobre o gênero a amostra desta fase esteve equiparada com $50 \%$ homens e $50 \%$ mulheres. Sobre a quantidade de carros próprios ou da família: $48 \%$ possuíam apenas um carro; $35 \%$, dois carros; $11 \%$, três carros; e $6 \%$, quatro ou mais carros à disposição para uso.

Além disto, tendo em vista que o objetivo nesta fase não foi limitar as marcas avaliadas, mas sim compreender a percepção sobre a marca de carro que o respondente tinha, 17 marcas diferentes foram citadas. Para conduzir a análise dos dados coletados nesta etapa preparatória, foi realizada inspeção de estatística descritiva univariada, por meio da conferência dos limites, médias, desvios padrão, assimetria e curtose dos indicadores de cada construto analisado. Também foi conferida a normalidade dos dados. Procedimentos semelhantes foram conduzidos em estudos anteriores (PRADO, 2004; FRANCISCOMAFFFEZZOLLI, 2007). Os principais resultados estão dispostos na tabela 1 e 2 . Na tabela 1 estão descritos todos os itens gerados inicialmente para a escala. Já na tabela 2 estão os itens que permaneceram para a etapa seguinte por apresentarem, de forma conjunta, maior ajuste e poder de explicação.

De acordo com a proposta teórica, a dimensão cognitiva foi elaborada com questões relativas ao conhecimento e experiência com a marca avaliada. Considerando a escala de 6 pontos, o nível de conhecimento foi aceitável com médias entre 3 e 5. Com alpha de 0,723 a dimensão ficou melhor ajustada com os itens 2, 3 e 4 . Tal situação implica que a avaliação sobre o conhecimento da marca em termos de valores, tradição e características diferenciais da marca, decorrentes da experiência do consumidor é fundamental para que haja a 
Identificação com a marca: proposição de um instrumento de medida

identificação com a marca (BURGESS; HARRIS, 1999). Sendo assim, o nível de cognição a respeito da marca interfere no processo de identificação, fato previsto na relação de identidade e consistência postulados na SIT e na SCT. Não se gosta ou não se estabelece congruência com o que não se conhece (SIRGY, 1986).

Tabela 1 - Apresentação descritiva do modelo de mensuração da identificação com a marca

\begin{tabular}{|c|c|c|c|c|}
\hline & Indicadores & $\mathrm{N}$ & Média & $\begin{array}{l}\text { Desvio } \\
\text { Padrão }\end{array}$ \\
\hline \multirow{4}{*}{ 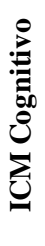 } & (IDC_1) Como você qualifica a sua experiência com a "Marca X"? & 193 & 4,66 & ,794 \\
\hline & $\begin{array}{l}\text { (IDC_2) Qual o seu nível de conhecimento sobre as características que diferenciam } \\
\text { a "Marca X" das demais marcas de carros? }\end{array}$ & 192 & 4,36 & 1,079 \\
\hline & $\begin{array}{l}\text { (IDC_3) Qual o seu nível de conhecimento sobre os VALORES institucionais (ex: } \\
\text { inovação, sustentabilidade, responsabilidade social, etc) da "Marca X"? }\end{array}$ & 192 & 3,23 & 1,357 \\
\hline & (IDC_4) Qual o seu nível de conhecimento sobre a TRADIÇÃO da "Marca X"? & 194 & 4,05 & 1,168 \\
\hline \multirow{7}{*}{ 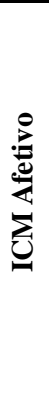 } & (IDA_1) Você se sente parte de uma comunidade de usuários da "Marca X"? & 187 & 3,58 & 1,425 \\
\hline & (IDA_2) Quanto você gosta da "Marca X"? & 193 & 5,16 & ,858 \\
\hline & $\begin{array}{l}\text { (IDA_3) Sendo usuário, como você se sente quanto alguém diz algo bom sobre a } \\
\text { "Marca X"? }\end{array}$ & 175 & 4,88 & ,729 \\
\hline & $\begin{array}{l}\text { (IDA_4) Quanto você sente que a imagem da "Marca X" é parecida coma sua } \\
\text { imagem pessoal? }\end{array}$ & 174 & 4,18 & 1,259 \\
\hline & (IDA_5) Como você se sente quando usa a "Marca X”? & 174 & 4,98 & ,760 \\
\hline & (IDA_6) Quanto você se identifica com outras pessoas que usama "Marca X"? & 173 & 3,97 & 1,472 \\
\hline & (IDA_7) Em geral, quais são os seus sentimentos sobre a "Marca X”? & 188 & 4,88 & ,906 \\
\hline \multirow{6}{*}{ 离 } & (IDAV_1) Para você, ser um usuário da “Marca X", é: & 181 & 4,73 & ,714 \\
\hline & (IDAV_2) Em geral, para o seu grupo social, ser um usuário da "Marca X", é: & 150 & 4,57 & ,781 \\
\hline & (IDAV_3) Ser admirado pelo seu grupo social por ser um usuário da "Marca X", é: & 119 & 4,37 & ,711 \\
\hline & (IDAV_4) Em geral, as pessoas veem a "Marca X" como: & 153 & 4,40 & ,781 \\
\hline & $\begin{array}{l}\text { (IDAV_5) Comparado com outras marcas, pessoas do seu grupo social veema } \\
\text { "Marca X" como: }\end{array}$ & 155 & 4,35 & ,811 \\
\hline & (IDAV_6) A percepção do seu grupo social sobre a "Marca X" é: & 163 & 4,62 & ,771 \\
\hline \multirow{6}{*}{ 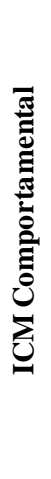 } & $\begin{array}{l}\text { (IDCm_1) Quando você compra a "Marca X", você acredita que a marca comprada } \\
\text { tem a ver com você? }\end{array}$ & 180 & 4,24 & 1,125 \\
\hline & $\begin{array}{l}\text { (IDCm_2) Com qual nível de frequência você costuma ir a eventos em que a "Marca } \\
\text { X' está envolvida? }\end{array}$ & 185 & 1,88 & 1,338 \\
\hline & $\begin{array}{l}\text { (IDCm_3) Com qual nível de frequência você participa de grupos virtuais } \\
\text { associados coma "Marca X"? }\end{array}$ & 183 & 1,63 & 1,241 \\
\hline & $\begin{array}{l}\text { (IDCm_4) Em geral, quando você fala da "Marca X" para outras pessoas, os } \\
\text { comentários são: }\end{array}$ & 165 & 4,65 & ,868 \\
\hline & $\begin{array}{l}\text { (IDCm_5) Com qual nível de frequência você costuma buscar informações sobre a } \\
\text { "Marca X"? }\end{array}$ & 169 & 3,04 & 1,469 \\
\hline & $\begin{array}{l}\text { (IDCm_6) Com qual frequência você costuma estar envolvido em atividades com } \\
\text { usuários da "Marca X"? }\end{array}$ & 164 & 1,90 & 1,344 \\
\hline
\end{tabular}

Legenda: Escala bietápica de 6 pontos. Valores próximos a 6 demonstram maior concordância e próximos a 1 menor concordância com as questões em teste.

IMC: Identificação com a Marca

Fonte: Elaborado pelos autores

A dimensão afetiva, já discutida na literatura acerca do afeto atribuído a uma marca (ZAMBARDINO; GOODFELLOW, 2007), também demonstrou médias entre 3 e 5 nas questões sobre o tipo de sentimento e sensação sentida acerca da marca escolhida para REAd | Porto Alegre - Edição 76 - N 3 - setembro/dezembro 2013 - p. 588-619 
Eliane Cristine Francisco Maffezzolli \& Paulo Henrique Muller Prado

avaliação. Como algumas questões continham traços de conteúdo similares, embora complementares, o modelo final foi composto pelos itens 2, 3, 4 e 6, com alpha de 0,779. Tais itens abordam o 'gostar da marca', a proximidade de imagem pessoal e da marca e a relação positiva de identificação com a marca, conforme destacado na SCT enquanto elementos que podem proporcionar autoestima e incitar a congruência (SIRGY, 1986).

Tabela 2 - Apresentação dos resultados da AFE e Alfa de Cronbach

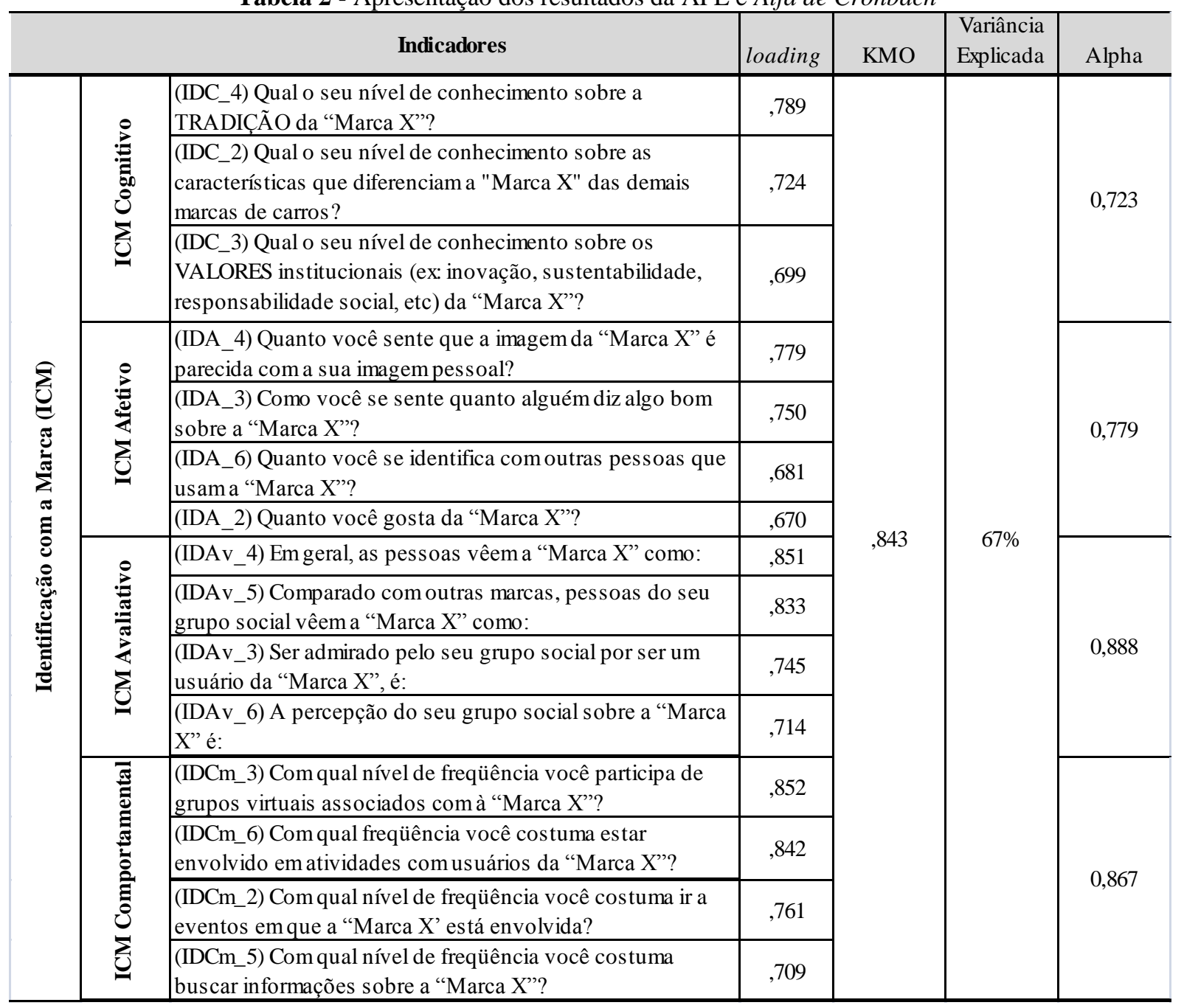

Fonte: Elaborado pelos autores

A dimensão avaliativa, importante na estrutura teórica da psicologia social e cognitiva, demonstra a avaliação de terceiros com grande relevância para explicar a sensação de bemestar com o uso da marca. Dos 6 itens gerados inicialmente, 3, 4, 5 e 6 com alpha de 0,888 foram mantidos na escala. Além da melhor adequação estatística, o conteúdo abordado pelos quatro itens parece representar eficientemente o sentido de avaliação no meio social. Afinal, o 
Identificação com a marca: proposição de um instrumento de medida

senso de pertença postulado na SIT é decorrente do reconhecimento e aceite do meio social (TAJFEL, 1984).

Por fim, a dimensão comportamental foi definida pela frequência e nível de interação do consumidor e marca consumida, conforme proposta conceitual de envolvimento com uma marca (WANN; BRASCOMBE, 1993; HEERE; JAMES, 2007). Neste caso, dos 6 itens gerados inicialmente, os que melhor explicam esta dimensão foram 2, 3, 5 e 6 com alpha de 0,867. Percebe-se que os valores médios de avaliação destes itens são os mais baixos, entre 1 e 2, fato que sugere um potencial a ser explorado pelos gestores de marketing, ou seja, prover espaços de engajamento do consumidor com a marca. Na terceira e última etapa do estudo 4 marcas foram escolhidas para comparação, conforme apresentado anteriormente na metodologia.

\subsection{Etapa 3: quantativo-descritiva}

$\mathrm{Na}$ terceira esta foram pesquisados 780 indivíduos curitibanos proprietários de carros, via abordagem pessoal. A amostra final foi composta da seguinte forma: Volkswagen $(\mathrm{N}=$ 202), Fiat $(\mathrm{N}=203)$, Renault $(\mathrm{N}=190)$ e Honda $(\mathrm{N}=185)$. A maior concentração de classe social independentemente da marca analisada esteve entre B2, B1, A2 e C1 (mais de 70\%). Em média $80 \%$ dos respondentes foram homens. Recorda-se que o método de coleta foi por abordagem pessoal sem cota de gênero, mas sim, cotas mínimas por marca avaliada conforme a disponibilidade do respondente. Em relação ao tempo de experiência pessoal com a marca, a média de anos entre proprietários foi de, aproximadamente, 7 anos para Volkswagen $(\mathrm{dp}=$ 88,747), 4 anos para Fiat $(d p=57,701), 3$ anos para Renault $(d p=30,874)$ e 3,5 anos para Honda $(\mathrm{dp}=41,077)$.

Após a análise descritiva e a AFE (novamente realizadas e com valores similares aos da segunda etapa), foi realizada a CFA dentre as dimensões da identificação com marcas. Os valores obtidos são considerados adequados e aceitáveis (HAIR JUNIOR et al., 2005): chisquare $=296,72, \mathrm{df}=84, \mathrm{p}$-value $<0,001, \mathrm{RMSEA}=0,057, \mathrm{NFI}=0,973, \mathrm{NNFI}=0,975, \mathrm{CFI}$ $=0,980, \mathrm{IFI}=0,980, \mathrm{RMR}=0,083, \mathrm{GFI}=0,898, \mathrm{AGFI}=0,855$. 


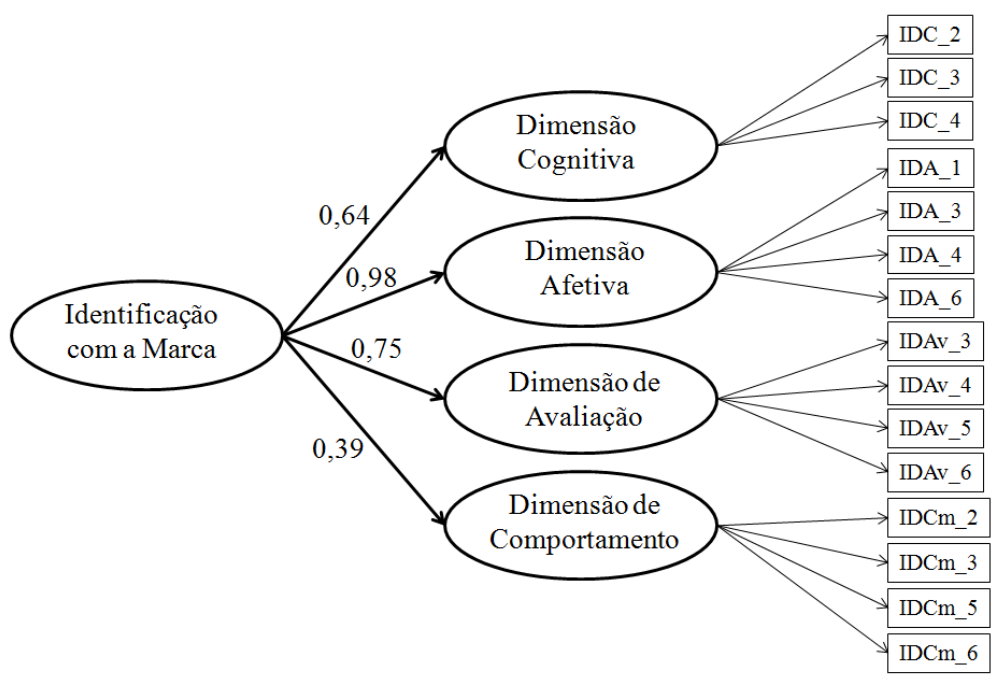

Figura 2 - Modelo de mensuração da identificação com marca (CFA de segunda ordem) Fonte: Tratamento de dados do estudo.

$\mathrm{Na}$ seqüência, foi verificado o modelo de mensuração sendo a identificação com a marca uma variável de segunda ordem, conforme ilustra figura 2. Os valores de ajuste do modelo são considerados adequados e aceitáveis (HAIR JUNIOR et al., 2005): chi-square = 328,84 , df $=86$, p-value $<0,001$, RMSEA $=0,060, \mathrm{NFI}=0,970, \mathrm{NNFI}=0,973, \mathrm{CFI}=0,978$, $\mathrm{IFI}=0,978, \mathrm{RMR}=0,095, \mathrm{GFI}=0,890, \mathrm{AGFI}=0,846$.

De acordo com os valores obtidos nos índices de Confiabilidade Composta e Variância Média Extraída, é possível afirmar que há validade convergente entre os indicadores medidos e as dimensões propostas. Além disto, no intuito de verificar a capacidade de discriminação entre as dimensões da identificação com as marcas, foram utilizados dois procedimentos: correlação entre as variáveis e o quadrado da correlação. Os valores da correlação (diagonal inferior da tabela 3) devem ser inferiores a 0,95 (HAIR JUNIOR et al., 2005), fato que comprova a não sobreposição de conceitos e medidas entre os construtos em análise. Já o quadrado das correlações correlação (diagonal superior da tabela 3) deve ser inferior ao AVE de cada dimensão, conforme ilustra o tabela 3:

Tabela 3 - Correlação entre as dimensões da identificação com a marca, AVE e Conf Composta

\begin{tabular}{lcccccc}
\hline Dimensões & Cognitiva & Afetiva & Avaliativa & Comportamental & AVE & Conf. Composta \\
Cognitiva & & 0,38 & 0,20 & 0,25 & 0,51 & 0,75 \\
Afetiva & 0,62 & & 0,57 & 0,13 & 0,50 & 0,80 \\
Avaliativa & 0,44 & 0,75 & & 0,06 & 0,62 & 0,86 \\
Comportamental & 0,50 & 0,36 & 0,24 & & 0,54 & 0,82 \\
\hline
\end{tabular}

Legenda: Diagonal inferior - correlação das dimensões da identificação com marca, significativas a p<0,001 
Identificação com a marca: proposição de um instrumento de medida

Diagonal superior - quadrado das correlações

AVE: Variância média explicada - valor de referência $>0,50$

Conf. Comporta: Confiabilidade composta - valor de referência $>0,70$

Fonte: Tratamento de dados do estudo.

De acordo com o poder de explicação dos dados obtidos na amostra coletada, observase no Quadro 3 a relevância do peso de cada indicador na respectiva dimensão (valores entre $35 \%$ e $79 \%$ ), tendo em vista que se trata de abordagem pioneira em relação a este construto.

Além disto, a tabela 4 também demonstra o peso na CFA e o valor $\mathrm{R}^{2}$ (poder de explicação) de cada dimensão. A perspectiva afetiva da identificação, da forma como foi mensurada, mostra ser um dos itens mais relevantes para explanar o fenômeno da identificação com a marca $\left(\mathrm{R}^{2}=97 \%\right)$, seguida das dimensões avaliativa $\left(\mathrm{R}^{2}=56 \%\right)$, cognitiva $\left(\mathrm{R}^{2}=42 \%\right)$ e comportamental $\left(\mathrm{R}^{2}=15 \%\right)$.

O menor valor, identificação comportamental, pode ter demonstrado tal resultado de acordo com o contexto empírico observado, já que as marcas pesquisadas não tem histórico de oferecer ações promocionais que convidem o consumidor a manter contato e envolvimento constante com a marca. Heere e James (2007) e Wann e Branscombe (1993) destacam a dimensão comportamental em relação a times de torcida de forma intensa, já que o indivíduo mostra adesão ao clube de várias formas, entre elas, adquirindo produtos e serviços da marca, filiando-se a comunidades presenciais e virtuais. Tal resultado demonstra uma área a ser melhor explorada por empresas do setor automobilístico já que implica na proximidade do individuo com a marca e, por consequência, pode estabelecer uma relação única com o consumidor e garantir vantagem competitiva. 
Eliane Cristine Francisco Maffezzolli \& Paulo Henrique Muller Prado

Tabela 4 - R² (poder de explicação) dos indicadores e de cada dimensão para a construção da identificação com

\begin{tabular}{|c|c|c|c|c|c|}
\hline & Indicadores & loading* & $\begin{array}{c}\mathrm{R}^{2} \text { do } \\
\text { indicador* }\end{array}$ & $\begin{array}{c}\text { Peso da } \\
\text { dimensão** }\end{array}$ & $\begin{array}{c}\mathrm{R}^{2} \mathrm{da} \\
\text { dimensão** }\end{array}$ \\
\hline \multirow{3}{*}{ 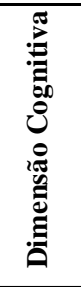 } & $\begin{array}{l}\text { (IDC_2) Qual o seu nível de conhecimento sobre as características } \\
\text { que diferenciam a "Marca X" das demais marcas de carros? }\end{array}$ & 0,65 & 0,42 & \multirow{3}{*}{0,64} & \multirow{3}{*}{0,42} \\
\hline & $\begin{array}{l}\text { (IDC_3) Qual o seu nível de conhecimento sobre os VALORES } \\
\text { institucionais (ex: inovação, sustentabilidade, responsabilidade } \\
\text { social, etc) da "Marca X"? }\end{array}$ & 0,74 & 0,55 & & \\
\hline & $\begin{array}{l}\text { (IDC_4) Qual o seu nível de conhecimento sobre a TRADIÇÃO da } \\
\text { "Marca X"? }\end{array}$ & 0,74 & 0,56 & & \\
\hline \multirow{4}{*}{ 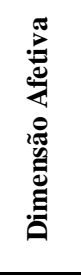 } & (IDA_2) Quanto você gosta da "Marca X"? & 0,72 & 0,51 & \multirow{4}{*}{0,98} & \multirow{4}{*}{0,97} \\
\hline & $\begin{array}{l}\text { (IDA_3) Como você se sente quanto alguém diz algo bom sobre a } \\
\text { "Marca X"? }\end{array}$ & 0,67 & 0,45 & & \\
\hline & $\begin{array}{l}\text { (IDA_4) Quanto você sente que a imagem da "Marca X" é parecida } \\
\text { com a sua imagem pessoal? }\end{array}$ & 0,74 & 0,55 & & \\
\hline & $\begin{array}{l}\text { (IDA_6) Quanto você se identifica com outras pessoas que usama } \\
\text { "Marca X"? }\end{array}$ & 0,67 & 0,45 & & \\
\hline \multirow{4}{*}{ 宽 } & $\begin{array}{l}\text { (IDAv_3) Ser admirado pelo seu grupo social por ser um usuário } \\
\text { da "Marca X", é: }\end{array}$ & 0,60 & 0,35 & \multirow{4}{*}{0,75} & \multirow{4}{*}{0,56} \\
\hline & (IDAv_4) Em geral, as pessoas veem a "Marca X" como: & 0,89 & 0,79 & & \\
\hline & $\begin{array}{l}\text { (IDAv_5) Comparado com outras marcas, pessoas do seu grupo } \\
\text { social veem a "Marca X" como: }\end{array}$ & 0,87 & 0,75 & & \\
\hline & (IDAv_6) A percepção do seu grupo social sobre a "Marca X" é: & 0,75 & 0,56 & & \\
\hline \multirow{4}{*}{ 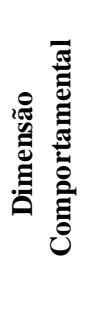 } & $\begin{array}{l}\text { (IDCm_2) Com qual nível de frequência você costuma ir a eventos } \\
\text { em que a "Marca X' está envolvida? }\end{array}$ & 0,82 & 0,67 & \multirow{4}{*}{0,39} & \multirow{4}{*}{0,15} \\
\hline & $\begin{array}{l}\text { (IDCm_3) Com qual nível de frequência você participa de grupos } \\
\text { virtuais associados comà "Marca X"? }\end{array}$ & 0,86 & 0,75 & & \\
\hline & $\begin{array}{l}\text { (IDCm_5) Com qual nível de frequência você costuma buscar } \\
\text { informações sobre a "Marca X"? }\end{array}$ & 0,62 & 0,38 & & \\
\hline & $\begin{array}{l}\text { (IDCm_6) Com qual frequência você costuma estar envolvido em } \\
\text { atividades com usuários da "Marca X"? }\end{array}$ & 0,61 & 0,38 & & \\
\hline
\end{tabular}

* valores da CFA de primeira ordem

** valores da CFA de segunda ordem

Fonte: Tratamento de dados do estudo.

Portanto, os valores obtidos neste estudo provocam a reflexão de três principais aspectos: (1) a identificação com marca é uma variável multidimensional; (2) a interpretação das quatro dimensões está coerente com as teorias de suporte (SIT e SCT), bem como com a constatação empírica; e (3) as dimensões da identificação com a marca contribuem com diferentes pesos para a compreensão do conceito global. O resultado encontrado avaliou apenas um único tipo de indústria. Estudos futuros podem testar a capacidade de explicação das dimensões propostas em diferentes setores. De acordo com a amostra coletada, no setor automobilístico, a dimensão afetiva é uma das mais relevantes, seguida da avaliativa. Tal situação sugere que desenvolver laços emocionais e simbólicos entre consumidor e marca pode prover maior identificação, bem como a presença e a aceitação do grupo social. Duas campanhas recentes da Volkswagen e da Fiat abordam estes temas, fato que está em 
Identificação com a marca: proposição de um instrumento de medida

consonância com os achados do estudo. A Volkswagen apostou no ano de 2012 com uma linha de comunicação do "selo de garantia", agregando maior valor, confiança e apego à marca enquanto critério de escolha de um carro. Já a Fiat apostou em comunicações que valorizam o meio social, como o caso do novo Línea. O modelo de executivo padrão, imagem do consumidor deste carro, é abordado com vários aspectos de aceitação social, como o terno, a gravata e o "Línea na garagem". Curlo e Chamblee (1998) encontraram uma forte relação entre a comunicação e os elementos persuasivos de uma campanha na estrutura de identificação.

\subsection{Discussão dos Resultados}

A proposição 1 deste estudo destaca a importância do conhecimento prévio que o indivíduo tem sobre uma determinada marca como país de origem, valores, princípio, tradição, entre outros (BURGESS; HARRIS, 1999; BREWER; HEWSTONE, 2004; HEERE; JAMES, 2007). Isto implica reconhecer que, quanto mais informações o indivíduo tem sobre uma marca, maior tende a ser a capacidade de julgamento sobre esta marca ser a melhor opção escolhida ou não. $\mathrm{O}$ valor de $(\beta=0,64 \mathrm{p}<0,001)$ comprova a presença positiva e significativa desta dimensão para reconhecer parte do processo de identificação. Ressalta-se ainda a importância desta faceta tendo em vista o processo de construção imaginário e simbólico que o indivíduo pode fazer acerca do conhecimento da marca. Conforme destacado por Heere e James (2007), o conhecimento de uma marca pode ser um fator determinante para sua escolha. Se a imagem da marca, construída pela experiência do consumidor, pelos comentários do mercado e pela mídia forem positivos, o consumidor passa a ter maior chance de sentir-se identificado com a marca, se seus valores pessoais, ambições, crenças e aspirações forem congruentes com seu perfil pessoal.

Quanto à proposição 2, relacionada à dimensão afetiva, foi observada o maior peso da relação com a identificação com a marca $(\beta=0,98$ p<0,001). Esta situação sugere a importância do vínculo emocional e afetivo entre marcas do setor automotivo e consumidores, tendo em vista a relevância simbólica que as marcas podem evocar, como status e desempenho. Outros estudos (HEERE; JAMES, 2007; FRANCISCO-MAFFEZZOLLI et al., 2008; GROHMANN, 2009) também evidenciam a importância da natureza afetiva na avaliação de marcas.

Portanto, para que o processo de identificação com as marcas aconteça, além do conhecimento da marca, as respostas afetivas como o 'gostar' da marca são relevantes. Foi REAd | Porto Alegre - Edição 76 - N 3 - setembro/dezembro 2013 - p. 588-619 
percebida na fase qualitativa, certa dificuldade para a pessoa explicar por quais motivos gosta da marca, conforme relato da Alice “(...) ah!, gosto porque gosto. Não sei explicar, apenas me sinto bem quando uso esta marca (trecho extraído do relato pela respondente 'Alice' quando falava sobre a Dove)". Isto implica reconhecer que o aspecto afetivo é complexo e, neste estudo, também demonstra o processo de simplificação para ser passível de ser medido. Heere e James (2007) avaliam a dimensão afetiva em contexto de times esportivos e elucidam que os motivos para 'gostar' podem ser variados. Portanto, cabe ao gestor da marca estimular o apelo afetivo positivo nas ações de marketing e nos pontos de contato com o consumidor. Sirgy (1986) também destaca o afeto como elemento positivo da congruência do self. Logo, temos a tendência de gostar daquilo que conhecemos e que nos faz sentir mais coesos nas decisões rotineiras.

Já a dimensão avaliativa, estruturada na proposição 3 , dedica-se à capacidade de comparação do uso de bens de consumo em relação a si próprio e às outras pessoas (ASHMORE; DEAUX; MACLAUGHLIN-VOLPE, 2004; HEERE; JAMES, 2007). No contexto observado, houve comprovação desta dimensão $(\beta=075 \mathrm{p}<0,001)$ principalmente no que tange à preocupação de avaliação e inserção social, conforme postulado por Tajfel (1984). Durante a fase qualitativa, espontaneamente os respondentes deram exemplos de situações de consumo que facilitava a interpretação da presença da marca nos grupos sociais, como entre familiares e grupos de trabalho.

Como quarta dimensão, a proposição 4 investigou o elemento comportamental da identificação com marca, ou seja, a frequência das ações do indivíduo em prol da marca, conforme proposto nos trabalhos de Wann e Brascombe (1993) e Heere e James (2007). Algumas situações foram colocadas em teste como a presença em comunidades reais e virtuais, participação em eventos, ou até mesmo a simples busca de informação, em relação à dedicação do tempo pessoal para aderir alguma atividade vinculada à marca. Novamente, apesar da comprovação estatística desta dimensão $(\beta=0,39$ p<0,001), os valores de adesão às atividades foram muito baixos (médias entre 1 e 3), independentemente da marca avaliada. Possivelmente, este resultado pode ser reflexo do setor automotivo, no qual a promoção de eventos, ou mesmo o incentivo à participação em redes sociais ainda é incipiente.

Por fim, de acordo com os resultados apresentados na figura 2 e nos quadros 2 e 3, é possível afirmar que o processo de identificação é refletido pelas quatro dimensões propostas neste estudo.

REAd | Porto Alegre - Edição 76 - N 3 - setembro/dezembro 2013 - p. 588-619 
Identificação com a marca: proposição de um instrumento de medida

\subsection{Comparativo da Identificação com a Marca}

O resultado da comparação da variável identificação com a marca dentre as marcas avaliadas pode ser observado na tabela 5 , com os valores de média e desvio padrão, e na figura 3. De acordo com o comparativo de médias realizado pela ANOVA, percebe-se que a marca que tem maior contraste de avaliação é a Honda em relação às demais marcas. A Honda demonstrou maior peso na avaliação cognitiva (conhecimento e experiência, $\mu=3,89$ ). Além disto, os respondentes demonstram 'gostar mais da marca' $(\mu=4,72)$ principalmente em relação à Fiat e Renault. Sobre a dimensão avaliativa a Honda foi a melhor avaliada dentre todas de forma significativa $(\mu=4,67)$, o que implica considerar que usar esta marca é um símbolo de reconhecimento, status e bem-estar para os respondentes em relação ao contexto social. No entanto, sobre a dimensão comportamental, todas as marcas demonstram baixos índices de envolvimento com o consumidor.

Tabela 5 - Diferença da média de avaliação das dimensões da identificação com a marca

\begin{tabular}{l|c|c|c|c|c}
\hline & VOLKSWAGEN (a) & FIAT (b) & HONDA (c ) & RENAULT (d) & F sig \\
\hline IDM: DIM COGNITIVA & $3,79(0,97) \boldsymbol{d}$ & $3,68(0,83)$ & $3,89(1,04) \boldsymbol{d}$ & $3,47(0,96) \boldsymbol{a} \boldsymbol{c}$ & $6,553 \mathrm{p}<0,000$ \\
\hline IDM: DIM AFETIVA & $4,55(0,83)$ & $4,45(0,86) \boldsymbol{c}$ & $4,72(0,80) \boldsymbol{b} \boldsymbol{d}$ & $4,43(0,85) \boldsymbol{c}$ & $4,739 \mathrm{p}<0,05$ \\
\hline IDM: DIM AVALIATIVA & $4,27(0,64) \boldsymbol{c}$ & $4,25(0,65) \boldsymbol{c} \boldsymbol{d}$ & $4,67(0,65) \boldsymbol{a} \boldsymbol{b \boldsymbol { d }}$ & $4,24(0,61) \boldsymbol{c}$ & $19,574 \mathrm{p}<0,000$ \\
\hline IDM: DIM COMPORTAMENTAL & $2,73(1,18) \boldsymbol{c}$ & $2,66(1,13)$ & $2,54(1,14)$ & $2,38(1,09) \boldsymbol{a}$ & $3,668 \mathrm{p}<0,05$ \\
\hline Total de respondentes & 202 & 203 & 185 & 190 & \\
\hline
\end{tabular}

Legenda: a, b, c, d são referências do resultado do teste de Sheffe

Fonte: Elaborado pelos autores

Dentre as marcas avaliadas a que demonstrou diferença significativa foi a Volkswagen em relação à Renault. Mesmo assim, ressalta-se que as médias foram baixas, considerando a escala de 6 pontos utilizada. Este fato sugere uma área de maior atenção dos gestores de marketing, já que reflete o envolvimento do consumidor com a marca e que pode ser potencializado por meio de plataformas digitais, como as redes sociais.

A figura 3 ilustra o baixo índice identificação comportamental declarado pelo consumidor, de acordo com as médias apresentadas na tabela 3. Dentre as marcas avaliadas percebe-se que a Renault está com os menores índices em todas as dimensões, apresentando diferenças significativas entre Volkswagen e Honda, fato que implica na baixa manifestação da identificação com a marca por parte dos respondentes. Já Volkswagen e Fiat demonstram avaliações similares entre si.

REAd | Porto Alegre - Edição 76 - Nº 3 - setembro/dezembro 2013 - p. 588-619 


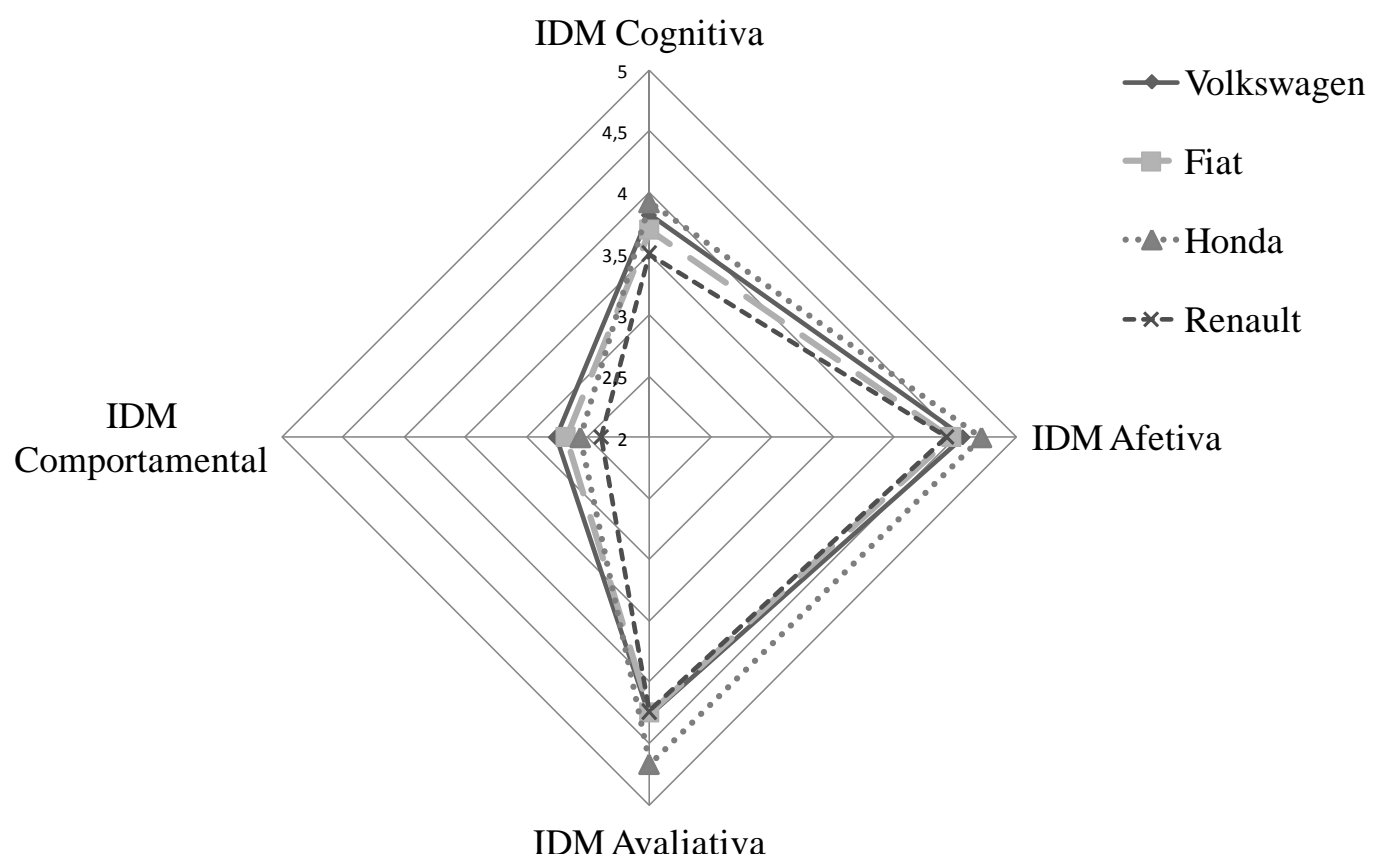

Figura 3 - Comparativo das dimensões da identificação com a marca Fonte: Elaborado pelos autores

Outra relação possível trata da tendência dos indivíduos com maior média de identificação permanecerem com marcas utilizadas, ou seja, aqueles que se dizem mais identificados com as marcas utilizadas tenderem a uma menor probabilidade de troca da marca, conforme ilustra a figura 4. Esta relação foi explorada neste estudo com a finalidade de demonstrar um dos benefícios possíveis do monitoramento e controle da identificação nas estratégias de marketing. Conforme apresentado neste estudo, o processo de identificação oferece à marca uma condição exclusiva de vantagem competitiva. Afinal, quando nos identificamos, quando temos afinidade e nos sentimos próximos a uma marca, existe maior tendência de permanecermos com ela em situações comerciais futuras. A figura 4 evidencia a vantagem da identificação sobre a probabilidade de troca da marca do carro em uma possível compra futura. 
Identificação com a marca: proposição de um instrumento de medida

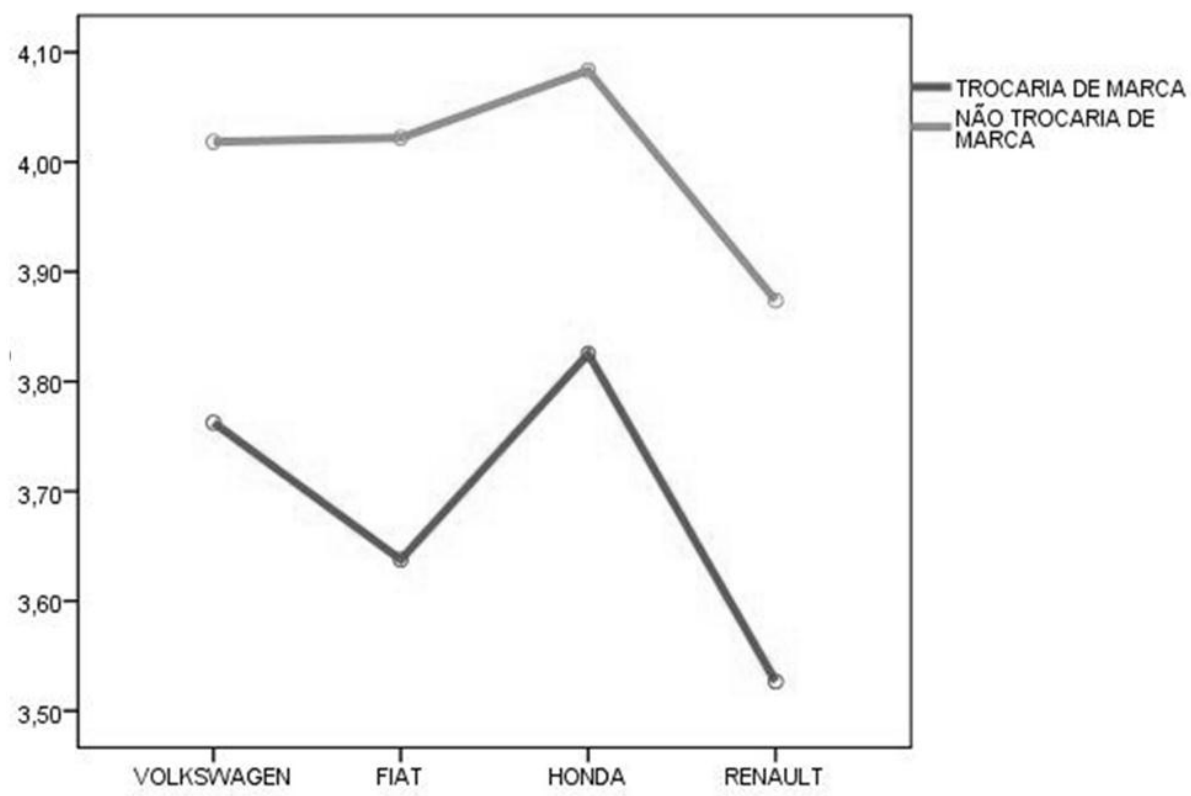

Figura 4 - Relação entre a propensão à troca e a identificação com a marca Legenda: Linha vertical $=$ média ponderada das dimensões da identificação com a marca Escala de identificação $=6$ pontos, sendo 1 não me identifico nada e 6 me identifico totalmente Fonte: Tratamento de dados do estudo

Conforme observado neste estudo, a identificação com marcas permite a compreensão sobre o 'quanto uma determinada marca tem a ver com o indivíduo'. Para isto, a psicologia cognitiva oferece ferramentas de avaliação sob o ponto de vista de conhecimento, afeto, avaliação e ação que a pessoa é capaz de desenvolver (MORALES et al., 2009).

\section{CONSIDERAÇÕES FINAIS}

As conclusões deste estudo são apresentadas de acordo com duas perspectivas: (1) a contribuição teórica do tema desenvolvido e (2) as contribuições gerenciais cabíveis a este estudo.

Do ponto de vista teórico, a identificação com a marca é uma variável que tem por objetivo mostrar o quanto uma marca está próxima da identidade de um indivíduo a ponto de reforçar sua imagem, estima e reconhecimento perante os grupos que este pertence. Estudos anteriores trataram de temas próximos, como a extensão do self com as marcas, relacionamento com as marcas e congruência de imagem entre consumidor e marca, mas não explicaram especificamente o fenômeno da identificação. (SIRGY, 1982; BELK, 1988; FOURNIER, 1998; FRANCISCO-MAFFEZZOLLI et al, 2008; PARKER, 2009).

De acordo com a base teórica de suporte e as constatações empíricas oriundas das três etapas de pesquisa, parece coerente a composição multidimensional deste construto, o que é

REAd | Porto Alegre - Edição 76 - N 3 - setembro/dezembro 2013 - p. 588-619 
original a este estudo. O elemento cognitivo reforça a capacidade de reconhecimento, interpretação e experiência do consumidor com a marca. Logo, sem exposição e experimentação, o processo de identificação fica comprometido.

O elemento afetivo aparece com relevância para explicar este fenômeno. Logo, as marcas devem prover empatia dentre os consumidores e estimular os vínculos mais profundos. A dimensão de avaliação revela uma importância única sobre a opinião pessoal e de terceiros sobre as definições tomadas acerca do self. Desta forma, é possível mencionar que somos produto das nossas escolhas, o que enfatiza a opinião pessoal, bem como reflexo do meio em que estamos, fato que reforça a opinião de terceiros sobre nosso self. Por fim, a questão comportamental sugere um esforço único e espontâneo em prol da marca. Cabe às marcas oferecerem espaços para que as ações tomem forma.

Em termos gerenciais, compreender o fenômeno de identificação com a marca permite ao gestor de marketing um parâmetro alternativo para a segmentação dos consumidores, bem como reconhecer o potencial que as campanhas promocionais podem alcançar em termos da proximidade e afinidade com o consumidor.

Tendo em vista que a dimensão cognitiva prevê o conhecimento e a experiência que a pessoa tem sobre determinada marca, as ações promocionais podem estimular a experiência do consumidor com as marcas direto no ponto de venda ou aproveitar a interatividade digital proporcionada desde o advento da web 2.0. Tais ações intencionam gerar sensações positivas no consumidor como usuário ou possível usuário da marca e, portanto, tendem a estimular o lado afetivo e emocional da identificação. Ressalta-se que esta perspectiva afetiva também está ligada ao aspecto simbólico que a marca pode construir em torno do valor percebido da marca. Além disto, tem-se ainda que, quanto mais positivo for o reforço avaliativo de terceiros, maior será o efeito no processo de identificação e maior será a chance da marca agregar valor junto ao consumidor. Tal constatação implica em reconhecer que o valor percebido da marca depende da avaliação pessoal, bem como da aceitação do meio em que o indivíduo se encontra. Por fim, cabe ressaltar a importância dos laços de envolvimento do consumidor com a marca, fato que é sugerido na dimensão comportamental da identificação. Ações de marketing podem oferecer ao consumidor benefícios pelo envolvimento em clubes especiais, programas de relacionamento ou mesmo destacar a importância do pertencimento a comunidades virtuais exclusivas da marca, estimulando o processo de identificação.

REAd | Porto Alegre - Edição 76 - N 3 - setembro/dezembro 2013 - p. 588-619 
Identificação com a marca: proposição de um instrumento de medida

\section{Limitações e Pesquisas Futuras}

Especialmente sobre a terceira etapa empírica não houve cota sobre gênero, portanto, os resultados são oriundos de uma amostra predominantemente masculina. Esta discrepância entre os entrevistados poderia ter sido evitada com o estabelecimento de cotas no início da coleta. Ressalta-se que as cotas foram criadas apenas de acordo com as marcas avaliadas, bem como com o perfil do respondente: avaliador e proprietário. Sendo assim, estudos futuros podem checar se há diferenças na avaliação entre gêneros. Além disto, também poderiam ter sido utilizadas cotas sobre o tipo de carro ou ainda sobre o valor monetário do bem (por exemplo: carros populares x carros de luxo). Sugere-se que bens com maior valor agregado permitem maior relação de identificação, fato que pode ser confirmado em um novo estudo. Ressalta-se ainda, conforme resultados obtidos na etapa qualitativa, que o processo de identificação não está associado a um único tipo de indústria. Logo, marcas em diversos setores podem ser contrastadas como vestuário, alimentício, higiene, entre outros.

\section{REFERÊNCIAS}

ANFAVEA.Anuário da Indústria Automobilística. São Paulo, 2013.

ASHMORE, R. D; DEAUX, K; MACLAUGHLIN-VOLPE, T. An organizing framework for collective identity: Articulation and significance of mltidimensionality. Psychological Bulletin, 130 (1), p.80-114, 2004.

BARDIN, L. Análise de conteúdo. 3. ed. Lisboa: Edições 70, 2004.

BELK, R.W. Possessions and the Extended Self. Journal of Consumer Research, v. 15, september, p.139-167, 1988.

BERGAMI, M.; BAGOZZI, R. P. Self-categorization, affective commitmet and groupselfesteem as distinct aspects of social identity in the organization. British Journal of Social Psychology, v. 39, p. 555-577, 2000.

BHATTACHARYA, C.; SEN, S.; Consumer-company identification: understanding consumer's relationships with companies. Journal of Marketing, v. 67, p. 76-88, 2003.

BREWER, M. B; HEWSTONE, M. Self and Social Identity. Blackwell Publishing, Oxford, 2004.

REAd | Porto Alegre - Edição 76 - N 3 - setembro/dezembro 2013 - p. 588-619 
BURGESS, S.M; HARRIS, M. Social identity in an Emerging consumer market: how do you do the wash may say a lot about who you think you are. Advances in Consumer Research, 26, p.170-175, 1999.

CURLO, E; CHAMBLEE, R. Ad processing and persuasion: The role of brand identification. Psychology \& Marketing. v. 15, n. 3, p. 279-299, 1998.

DIMMOCK, J. A.; GROVE, J. R.; EKLUND, R. C. Reconceptualizing team identification: new dimensions and their relationship to intergroup bias. Group Dynamics: Theory, Research and Practice, v. 9, n. 2, p. 75-86, 2005.

DOLICH, I. J. Congruence relationships between self images and product brands. Journal of Marketing Research, v. 6, p. 80-84, 1969.

ESCALAS, J. E.; BETTMAN, J. R. Self-Construal, Reference Groups, and Brand Meaning. Journal of Consumer Research, p. 378-389, 2005.

FOURNIER, S. Consumers and their brands: Developing relationship theory in consumer research. Journal of Consumer Research, 24 (1), p.343-373, 1998.

FRANCISCO, E. C. Impacto da lealdade e da qualidade do relacionamento no resultado financeiro dos clientes: estudo no setor de telefonia celular. 238f. 2007. Dissertação (Mestrado em Administração) - Universidade Federal do Paraná, Curitiba, 2007.

FRANCISCO-MAFFEZZOLLI, E.C; MADY, E.B; BRUNETTA, D; LIMA, M.V.V; FABRIS, C; SANTOS, T. Um Modelo Conceitual das Relações entre Sentimentos, Intimidade, Interdependência e Autoconexão do Consumidor com Marcas. III Encontro de Marketing da ANPAD, maio, 2008.

FRANCISCO-MAFFEZZOLLI, E. C.; PRADO; P. H. M.; MONTAÑA, J. Building the brand identification concept. In: ANNUAL CONFERENCE OF THE SPECIAL INTEREST GROUP ON BRAND, IDENTITY AND CORPORATE REPUTATION OF THE ACADEMY OF MARKETING. 6. 2010. Conference... Working paper: Barcelona, Spain. ESADE, 2010.

GROHMANN, B. Gender dimensions of brand personality. Journal of Marketing Research, v. 46, p. 105-119, 2009. 
Identificação com a marca: proposição de um instrumento de medida

HAIR Jr, J. F.; ANDERSON, R.E..; TATHAM, R.L; BLACK, W. Multivariate Data Analysis. ed 5, Nova York: Prentice Hall, 2005.

HEERE, B; JAMES, J. D. Stepping Outside the Lines: Developing a Multi-dimensional team Identity scale based on Social Identity Theory. Sport Management Review, v.10, p.65-91, 2007.

HILDEBRAND, D. F. N. et. al. Consumer-company identification: development and validation of a scale. In: ENCONTRO DE MARKETING. 3. 2008, Curitiba. Anais...Curitiba: ANPAD, 2008.

KUENZEL, S; HALLIDAY, S.V. Investigating antecedents and consequences of brand identification. Journal of Product \& Brand Management. v.17, n.5, p.293-304, 2008.

LISJAK, M ; LEE, A. Y ; GARDNER, W. L. When a Threat to the Brand Is a Threat to the Self. Personality and Social Psychology Bulletin, v.38 (9), p.1120-1132, 2012.

MALHOTRA, N. K. Pesquisa de marketing: uma orientação aplicada. 4. ed. Porto Alegre: Bookman, 2006.

MITTAL, B. I, me and mine - how products become consumers' extended selves. Journal of Consumer Behavior., p.550-562, 2006.

MORALES, J.F; MOYA, M; GAVIRA, E; CUADRADO, I. Psicología Social. 3ed. McGraw-Hill: Espanha, 2007.

MOWER, W.C. J. Consistency in cognitive social behavior. An introduction to Social Psychology. Routledge \& Kegan Paul ltda, Boston, 1982.

PAWLE, John; COOPER, Peter. Measuring Emotion - Lovemarks, The Future Beyond Brands. Journal of Advertising Research. p.38-50, 2006.

PARKER, B. T. A comparison of brand personality and brand user-imagery congruence. Journal of Consumer Marketing, v. 26, n. 3, p. 175-184, 2009. 
PRADO, P. H. M. A avaliação do relacionamento sob a ótica do cliente: um estudo em bancos de varejo. 2004. 497 f. Tese (Doutorado em Administração) - Fundação Getúlio Vargas, São Paulo, 2004.

SIRGY, J. M. Self-Concept in Consumer Behavior: A Critical Review. Journal of Consumer Research. v. 9, p.287-291, 1982.

SIRGY, J.M. Self-Congruity: Toward a Theory of Personality and Cybernetics. Praeger, New York: 1986.

SCHOUTEN, J. W.; MCALEXANDER, J. H. Subcultures of consumption: an ethnography of the new bikers. Journal of Consumer Research, v. 22. p. 43-61, 1995.

STOKBURGER-SAUER, N. E. The relevance of visitors' nation brand embeddedness and personality congruence for nation brand identification, visit intentions and advocacy. Tourism Management, Vol.32(6), pp.1282-1289, 2011.

TAJFEL, H. Grupos humanos y categorías sociales. Estudios de psicología social. Barcelona, Editorial Herder, 1984.

TILDESLEY, A. E. COOTE, L. V. This Brand is Me: A Social Identity Based Measure of Brand Identification. Advances in Consumer Research. 36, p. 627-628, 2009.

TUŠKEJ, U; GOLOB, U; PODNAR, K. The role of consumer-brand identification in building brand relationships. Journal of Business Research, 66 (1), p.53-59, 2013

UNDERWOOD, R; BOND, E; BAER, R. Building service brands via social identity: Lessons from the marketplace. Journal of Marketing Theory and Practice. 9 (1), p1-13, 2001.

ZAMBARDINO, A; GOODFELLOW, J. Being "Affective" in Branding? Journal of Marketing Management. v23, n1-2, p27-37, 2007.

WANN, D.L; BRANSCOMBE, N.R. Sport fans: Measuring degree of identification with their time. International Journal of Sport Psychology, v.24, p.1-17, 1993. 